\title{
Total Synthesis of Four Stereoisomers of Acaterin through a Te/Li Exchange Protocol
}

\author{
Renan S. Ferrarini ${ }^{\star}$, Alcindo A. Dos Santos and João V. Comasseto \\ Instituto de Química, Universidade de São Paulo, São Paulo/SP, Brazil \\ *renan_ferrarini@yahoo.com.br
}

Keywords: Te/Li exchange reaction, butenolides, Acaterin

\section{INTRODUCTION}

Acaterin $^{1}$ (1) is an inhibitor of Acylcoenzyme A cholesterol acyl transferase (ACAT). It was first isolated from a culture of Pseudomonas $s p$. This type of inhibitor has a promising role in the treatment of atherosclerosis. The butenolide skeleton with an $\alpha$-alkyl chain, can be obtained from $\gamma$-butyl-telluro-allylic alcohols by $\mathrm{Te} / \mathrm{Li}$ exchange reaction and capture with $\mathrm{CO}_{2}$ according to a methodology recently established in our group. ${ }^{2}$

\section{RESULTS AND DISCUSSION}

Initially, the alkynones $\mathbf{4 a}$ and $\mathbf{4 b}$ were prepared from enantiopure OMEM-3-decinols 3a and $\mathbf{3 b}$, respectively by deprotonation of the acetylene portion, addition to acetaldehyde and Jones oxidation of the intermediate alcohols (Scheme 1).
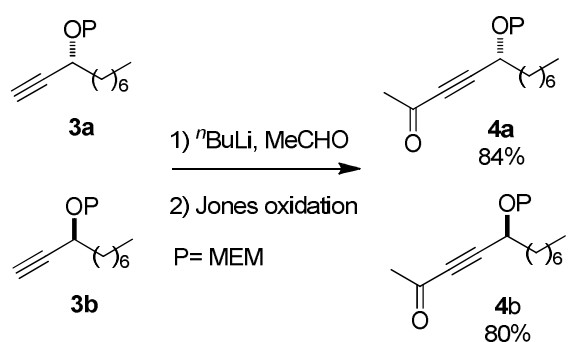

Scheme 1. Preparation of alkynones $\mathbf{4 a}$ and $\mathbf{4 b}$.

The alkynones $\mathbf{4 a}$ and $\mathbf{4 b}$ were submitted to a hydrotelluration reaction and the products were reduced with $\mathrm{NaBH}_{4}$, providing the diastereoisomeric mixtures $(1: 1)$ of $\gamma$-butyl-telluro-allyl alcohols $5 \mathbf{a}$ and 5b (Scheme 2).

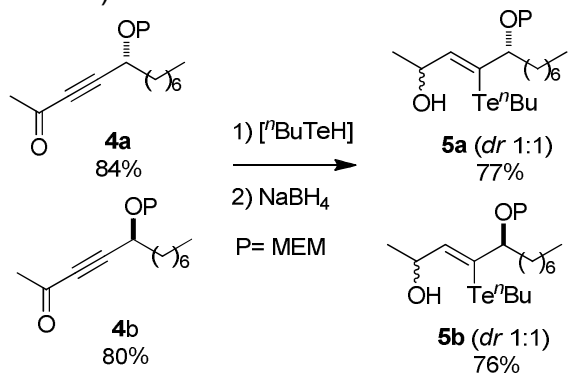

Scheme 2. Preparation of organotellurides $\mathbf{5 a}$ and $\mathbf{5 b}$.
The $\gamma$-butyl-telluro-allyl alcohols $\mathbf{5 a}$ and $\mathbf{5 b}$ were submitted to a Te/Li exchange reaction, generating a 1,4-C,O lithium dianionic intermediates, which on reaction with $\mathrm{CO}_{2}$ and subsequent acid hydrolysis yielded the diastereoisomeric mixtures $6 \mathbf{a}$ and $6 \mathbf{b}$. In the next step, the MEM group was removed $^{3}$, yielding the enantiopure forms of four stereoisomers of Acaterin after purification by flash chromatography (Scheme 3)

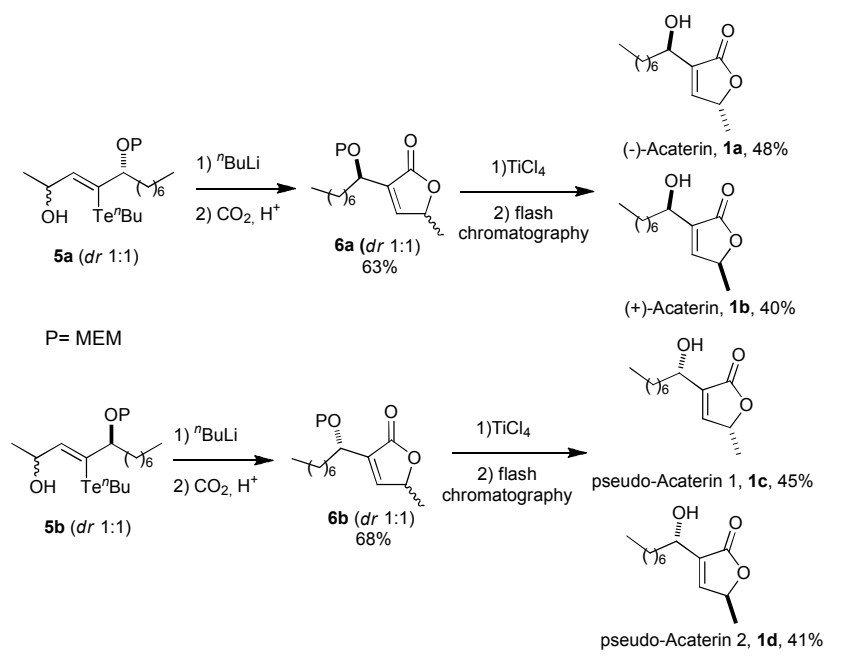

Scheme 3. Preparation of four stereoisomers of Acaterin (1a-d)

\section{CONCLUSION}

The four stereoisomers of Acaterin were prepared and isolated in a few synthetic steps, using a $\mathrm{Te} / \mathrm{Li}$ exchange reaction as the key step.

\section{ACKNOWLEDGEMENTS}

The authors thank FAPESP, CAPES and CNPq for the financial support.

\section{REFERENCES}

${ }^{1}$ Naganuma, S.; Sakai, K.; Hasumi, K.; Endo, A. J. Antibiotics 1992, 45, 1216.

${ }^{2}$ Ferrarini, R. S.; Dos Santos, A. A.; Comasseto, J. V. Tetrahedron Lett. 2010, 51, 6843. 
${ }^{3}$ Anand, R. V.; Barktharaman, S.; Singh, V. K. Tetrahedron Lett. 2002, 43 , 